\title{
Quando e como valorizar culturas de urina polimicrobianas no laboratório de microbiologia clínica
}

Primeira submissão em 25/03/10 Última submissão em 25/05/10 Aceito para publicação em 25/05/10 Publicado em 20/08/10

\author{
When and how to enhance polymicrobial urine cultures at the laboratory of clinical microbiology
}

Alessandro Conrado de Oliveira Silveira'; Helena Aguilar Peres Homem de Mello de Souza²; Fábio Daniel Furtado 3 ; Bárbara Pereira Albini ${ }^{4}$; Carlos Augusto Albini ${ }^{5}$

\section{unitermos \\ Infecção urinária \\ polimicrobiana \\ Gram de urina não centrifugada \\ Urocultura polimicrobiana}

\section{resumo}

Introdução: Na maioria dos laboratórios de Microbiologia considera-se contaminação uma cultura de urina com mais de um morfotipo colonial, ignorando-se o desenvolvimento ou solicitando-se novo material. Raramente o isolado é considerado significativo. Objetivos: Com a finalidade de estudar as infecções urinárias polimicrobianas, no período de agosto de 2003 a janeiro de 2004, na cidade de Tubarão, Santa Catarina, foram selecionadas 117 amostras de urina de pacientes internados no Hospital Nossa Senhora da Conceição, de ambos os sexos, com idades que variavam de 14 a 98 anos. Métodos: Realizou-se uma análise minuciosa dos prontuários dos pacientes. Procedeu-se o Gram da gota de urina não centrifugada e a cultura com alça calibrada de 1 ou $10 \mu$ em ágar CLED (cistina-lactose deficiente em eletrólitos). Todas as culturas foram repetidas com nova coleta de urina com supervisão direta. Os clínicos aguardaram a segunda coleta (confirmatória) para iniciar a antibioticoterapia. Descartaram-se os pacientes que iniciaram a antibioticoterapia imediatamente após a primeira coleta ou que estavam utilizando antimicrobianos. Resultados: Obteve-se o total de seis $(12,8 \%)$ culturas polimicrobianas confirmadas, em um universo de 47 amostras com crescimento bacteriano estudadas. Os resultados foram compatíveis com as indicações clínicas. Conclusão: É importante ressaltar a correlação entre os achados laboratoriais e as indicações clínicas dos pacientes. Recomenda-se avaliar criteriosamente isolados polimicrobianos em amostras de urina, sejam ambulatoriais ou hospitalares.

\section{abstract}

Introduction: In most microbiology laboratories, a urine culture is regarded as contaminated when there is more than one colonial morphotype, thus either it is ignored or a new sample is requested. The isolate is rarely considered significant. Objectives: In order to study the polymicrobial urinary tract infections, 117 urine samples were selected from inpatients of both genders aged from 14 to 98 years old at Nossa Senhora da Conceição Hospital, Tubarão city, Santa Catarina, Brazil, from August 2003 to January 2004. Methods: A detailed analysis of patients' records was carried out. Gram test of non-centrifuged urine drop and culture with calibrated loop of 1 or 10 microliters in CLED agar were performed. All cultures were repeated with new urine collection under direct supervision. Physicians waited for the second collection (confirmatory test) to initiate antibiotic therapy. Patients that had started antibiotic therapy immediately after the first collection or those that were using antibiotics were discarded. Results: Six polymicrobial cultures were confirmed from a total of 47 samples with bacterial growth. The results were consistent with clinical indications. Conclusion: It is important to emphasize the correlation between laboratory findings and patients' clinical indications. It is recommended that polymicrobial isolates in urine samples from both out-patients and inpatients should be thoroughly investigated. key words

Polymicrobial urinary tract infection

Urine Gram uncentrifuged

Urine polymicrobial

1. Mestre em Ciências Farmacêuticas; professor de Microbiologia Clínica do Departamento de Ciências Farmacêuticas da Fundação Universidade Regional de Blumenau (FURB).

2. Mestra em Microbiologia, Parasitologia e Patologia; bioquímica do Hospital de Clínicas da Universidade Federal do Paraná (HC-UFPR).

3. Especialista em Microbiologia; bioquímico do Laboratório Bioclínico de Tubarão-SC.

4. Especialista em Tecnologia e Cestão Farmacêutica; coordenadora da garantia de qualidade do Newprov Produtos para Laboratório Ltda.

5. Mestre em Educação; professor do departamento de Patologia Médica da UFPR. 


\section{Introdução}

As uroculturas são os procedimentos responsáveis pela maior parte do trabalho dentro de um laboratório de microbiologia ${ }^{(1)}$. Vários sistemas comerciais vêm sendo desenvolvidos para a identificação de uropatógenos, visando diminuir custos, facilitar e agilizar o trabalho. Assim, pode-se afirmar que, na maioria dos casos, os uropatógenos podem ser isolados e identificados sem maiores problemas. Presume-se tratar-se de um exame simples, de fácil execução e interpretação.

Provavelmente tal ideia esteja embutida no pensamento de muitos profissionais, considerando, por exemplo, que uma cultura de urina deve ser essencialmente monobacteriana e quando há mais de um micro-organismo deve-se valorizar aquele em maior quantidade, desprezando os demais, sob justificativa de representarem contaminantes de coleta.

Até o momento, surpreendentemente, poucos estudos avaliaram a significância clínica de um crescimento polimicrobiano na urina. Tal significância foi demonstrada em alguns estudos pela recuperação da mesma combinação de micro-organismos no sangue e na urina, nos casos de urosepse, ou pela reprodutibilidade da mesma sequência de bactérias em repetidas culturas de urina ${ }^{(9)}$.

Deve-se considerar que as infecções urinárias verdadeiramente polimicrobianas não são muito comuns, embora não raras, em especial quando se trata de pacientes em situações específicas, como, por exemplo, pielonefrite, prostatite e cateterismo urinário, em que a incidência aumenta consideravelmente ${ }^{(10)}$.

Alguns fatores de complicação (sondas de nefrostomia, cálculos urinários e bexiga neurogênica) não só facilitam a entrada e a permanência de micro-organismos nas vias urinárias como também alteram o espectro de uropatógenos. Embora Escherichia coli seja a maior causadora de infecções do trato urinário (ITUs) complicadas e não complicadas, seguida de outros bacilos Gram-negativos (BGNs), como Enterobacter spp., Serratia spp., Acinetobacter spp. e Pseudomonas spp., é possível observar mais frequentemente micro-organismos que não seriam classificados como uropatógenos, como estafilococos coagulase negativos e leveduras, principalmente entre pacientes sob terapia antibacteriana e/ou uso de cateteres. Tais organismos, exceto $E$. coli, têm menor habilidade intrínseca para invadir o trato urinário intacto, mas podem se comportar como patógenos potentes quando são diminuídas as defesas do organismo. A ITU polimicrobiana, que em outros contextos é frequentemente considerada sugestão de contaminação de amostra, é comum em ITU complicada ${ }^{(3)}$.

A confirmação do diagnóstico polimicrobiano deveria ser realizada a partir da cultura de uma amostra adicional de urina obtida por punção suprapúbica. Tal procedimento, embora ideal, não encontra sustentação científica na prática atual pelo fato de se tratar de um procedimento invasivo. A obtenção de amostras seriadas de urina poderia ser uma alternativa adequada, entretanto é comum na rotina clínica a administração precoce de antimicrobianos em pacientes com suspeita de ITU. Assim, parece fundamental a agregação de critérios mais precisos ao exame bacteriológico de urina, visando verificar e qualificar as amostras de urina que contenham mais de um micro-organismo.

A interpretação utilizada para testes rotineiros consiste em: isolamentos de uma única espécie com crescimento bacteriano superior a 100 mil unidades formadoras de colônia por mililitro (UFC/ml) indicam infecção; inferior a $10.000 \mathrm{UFC} / \mathrm{ml}$ sugerem contaminação vaginal ou uretral; entre 10.000 e $100.000 \mathrm{UFC} / \mathrm{ml}$ são duvidosas, tornandose necessária avaliação com base na informação médica. A maioria dos casos de pielonefrite e cistite pode ser avaliada corretamente usando esses parâmetros. Tais diretrizes, porém, falham em alguns pacientes sintomáticos, considerando que alguns casos com contagens de $100 \mathrm{UFC} / \mathrm{ml}$ podem ser clinicamente relevantes.

Deve-se ter especial atenção às amostras de crianças, em que a coleta pode ser mais difícil e infecções podem se manifestar em contagens mais baixas $(1.000 \mathrm{a}$ $10.000 \mathrm{UFC} / \mathrm{ml}$ ). Infecções são encontradas mais frequentemente em indivíduos com anormalidades anatômicas e em crianças prematuras. É necessário estar atento também a pacientes com bexiga neurogênica e idosos que recebam cuidados domiciliares de enfermagem. Para tais indivíduos, testes de triagem não são precisos e a prevalência de bacteriúria é alta nos assintomáticos (30\%) e sintomáticos (60\%). Assim, recomenda-se semear a urina com alça calibrada de 0,001 $\mathrm{ml}$ e 0,01 ml, em sangue de carneiro a 5\%, ágar MacConkey e ágar Chocolate (se necessário), incubando a placa no mínimo por 48 horas, devendo-se considerar o crescimento de um ou mais organismos com densidade de 100 a $10.000 \mathrm{UFC} / \mathrm{ml}^{(3)}$.

Siegman-Igra ${ }^{(9)}$ observou que entre 61 pacientes com urosepse e urinas polimicrobianas 14 apresentavam processos de malignidade, 10 tinham doenças crônicas e severas do coração, nove eram pacientes debilitados neurologicamente, nove possuíam hipertrofia prostática 
benigna, três tinham diabetes mellitus, três apresentavam causas diversas e cinco eram pacientes com doenças desconhecidas.

Tem sido possível observar, na maioria dos laboratórios clínicos, que as uroculturas com crescimento polimicrobiano são tratadas como contaminações. É evidente que a contaminação de amostras ainda é algo muito comum, até pela falta de informação dada ao paciente em qualquer serviço, seja hospitalar ou ambulatorial. Entretanto, um protocolo minucioso de coleta obriga o analisador a ter mais critério antes de descartar uma amostra polimicrobiana.

O objetivo deste trabalho é determinar a incidência de infecções polimicrobianas no Hospital Nossa Senhora da Conceição, validando, com critérios específicos, as uroculturas polimicrobianas.

\section{Métodos}

Este estudo foi submetido ao comitê de ética do Hospital Nossa Senhora da Conceição, em Tubarão, Santa Catarina, em julho de 2003, sendo aprovado em agosto do mesmo ano.

Foram utilizadas 117 amostras de urina coletadas de pacientes de ambos os sexos, com idades que variavam entre 14 e 98 anos, internados no Hospital Nossa Senhora da Conceição no período de agosto de 2003 a janeiro de 2004. A coleta das amostras foi supervisionada ou realizada por enfermeiros devidamente treinados, de modo a dominarem as técnicas de coleta adequadas. Foi estabelecido um protocolo rígido de coleta a ser seguido.

Os materiais biológicos necessários foram coletados em duplicata, com supervisão direta, sendo que a segunda amostra só foi obtida após duas horas de retenção urinária pelo paciente. Tal procedimento ajuda a avaliar as amostras que forem sugestivas de infecção urinária mista, visto que a coincidência de resultados no Gram e na cultura de urinas coletadas em diferentes horários pode sugerir a hipótese de infecção urinária mista.

Ao chegar ao laboratório, as amostras foram conservadas em geladeira e processadas em no máximo 2 horas. Foi realizada a coloração de Gram da gota de urina não centrifugada ${ }^{(2)}$ com o objetivo de escolher a alça calibrada adequada e avaliar a microbiota predominante, a presença de leucócitos e as células do epitélio vaginal. As placas foram incubadas em estufa bacteriológica por 18 a 24 horas. Analisaram-se as colônias com o objetivo de evidenciar uroculturas polimicrobianas.
Para a identificação dos isolados foram utilizadas provas bioquímicas tradicionais ${ }^{(8)}$.

\section{Resultados}

$\mathrm{Na}$ análise das 117 amostras de urina foram encontradas 47 amostras $(47 / 117 ; 40,2 \%)$ com crescimento bacteriano. Nove $(9 / 47 ; 19,5 \%)$ apresentaram crescimento misto. Em três $(3 / 47 ; 6,4 \%)$ o desenvolvimento teve origem de contaminação, pois o confrontamento do resultado das culturas não foi satisfatório, havendo discrepância no crescimento bacteriano das amostras coletadas. Em seis amostras (6/47; $12,8 \%$ e $6 / 117 ; 5,2 \%)$ foi confirmada a presença de microbiota mista bacteriana.

A idade média dos pacientes que apresentaram culturas com crescimento bacteriano múltiplo foi de 61,2 anos (de 48 a 76 anos), sendo que $66,7 \%$ pertenciam ao sexo masculino e $33,3 \%$ ao feminino.

\section{Prevalência dos 47 micro-organismos}

Tabela 1 isolados

\begin{tabular}{l|c}
\hline Micro-organismo & Prevalência \\
\hline E. coli & 20 \\
K. pneumoniae & 8 \\
S. aureus & 4 \\
Enterobacter ssp. & 4 \\
Candida sp. & 3 \\
A. baumannii & 2 \\
S. epidermidis & 2 \\
Estreptococos do grupo D & 1 \\
não enterococos & \\
Outros & 3 \\
\hline
\end{tabular}

Foi notada a presença marcante de cepas de $K$. pneumoniae e E. coli, cada uma presente em 50\% (3/6) dos casos de infecção polimicrobiana. Nos mesmos casos, a incidência de Enterobacter spp. foi de 16,7\% (1/6) e de $33,3 \%(2 / 6)$ para S. epidermidis. O isolamento de Candida sp. e estreptococos do grupo $D$ não enterococos ocorreu na mesma proporção, ou seja, em 16,7\% (1/6) das amostras em questão, constituindo o grupo de bactérias presentes nas infecções polimicrobianas detectadas. Observou-se a associação entre isolados de $E$. coli e K. pneumoniae, assim como entre todos os outros micro-organismos isolados.

A contagem das colônias microbianas nos casos de interesse esteve sempre entre $10^{3}$ e $10^{5} \mathrm{UFC} / \mathrm{ml}$ e, na maioria 
dos casos $(83,3 \%$ ou $5 / 6)$, pouco variou entre a primeira e a segunda amostra. A correlação entre o Gram de gota de urina não centrifugada e o crescimento microbiano esperado, de acordo com a alça calibrada escolhida, mostrou-se eficaz, porém surgiram dificuldades quando se obteve mais de uma bactéria com semelhanças morfológicas (p. ex.: duas bactérias, BGNs), em que, além de atenção, foram necessárias também prática e experiência para a escolha correta da alça a ser usada.

Frequência dos micro-organismos isolados Tabela 2 nas culturas polimicrobianas

\begin{tabular}{l|c}
\hline Micro-organismo & Frequência (\%) \\
\hline E. coli & 50 \\
K. pneumoniae & 50 \\
S. epidermidis & 33,3 \\
Candida sp. & 16,7 \\
Estreptococos do grupo D & 16,7 \\
não enterococos & \\
Enterobacter ssp. & 16,7 \\
\hline
\end{tabular}

Fatores de risco, como diabetes, neoplasia prostática, uso de sonda de Foley por tempo prolongado, ITU complicada por retenção urinária e longos períodos em unidade de terapia intensiva (UTI), foram constatados isolados ou concomitantes nos pacientes com ITU polimicrobiana confirmada. Tais fatores foram, provavelmente, preponderantes para o desenvolvimento do quadro clínico em questão.

\section{Tabela 3 polimicrobianas}

\begin{tabular}{l|c}
\hline Fator de Risco & Frequência (\%) \\
\hline Diabetes & 50 \\
Retenção urinária & 16,7 \\
Longa permanência em UTI & 50 \\
Cateter urinário & 83,3 \\
ITU de repetição & 33,3 \\
Hipertensão arterial & 50, \\
Citostomia & 16,7 \\
Neoplasia prostática & 33,3 \\
\hline
\end{tabular}

ITUs: infecções do trato urinário; UTI: unidade de terapia intensiva.

Entre os pacientes com infecção urinária mista, metade (3/6) estava internada por tempo prolongado em UTI e a outra metade tinha hipertensão arterial. Convém citar que $33,3 \%(2 / 6)$ apresentavam ITU de repetição.
Do total de amostras analisadas, 36,75\% (43/117) foram provenientes de pacientes cateterizados; e do total de amostras com crescimento polimicrobiano, 83,3\% (5/6) foram obtidas de pacientes cateterizados.

Entre os pacientes estudados, 50\% (3/6) eram diabéticos. Outros 33,3\% (2/6) apresentavam neoplasia prostática. Retenção urinária estava presente em 16,7\% (1/6) dos casos constatados, a mesma quantidade encontrada para cistostomia (sonda ligada diretamente à bexiga, perfurando o abdome), um método pouco usado, mas uma porta de entrada para bactérias e outros micro-organismos.

\section{Discussão}

Neste estudo obteve-se 48,8\% (21/43) de crescimento microbiano em pacientes cateterizados, sendo que $11,6 \%$ (5/43) foram polimicrobianos. Goldman e Ausiello(4) alertaram que cerca de $50 \%$ das infecções hospitalares originamse no trato urinário pelo uso de cateter urinário. Analisando os dados, nota-se que as informações se completam, visto o alto grau de infecções causadas pelo cateterismo, e que infecções urinárias podem evoluir para sepse.

O resultado observado de que $48,8 \%$ dos pacientes cateterizados adquiriram ITU diverge com as informações publicadas por Henry ${ }^{(5)}$, que postula o desenvolvimento de bacteriúria associada ao procedimento em $1 \%$ para homens ambulatoriais. A diferença entre os resultados provavelmente se deve ao universo dos pacientes estudados, visto que os ambulatoriais podem ser julgados como saudáveis, enquanto os hospitalizados geralmente estão imunodeprimidos.

Os dados obtidos comprovam a relevância do risco de adquirir ITU complicada pelo uso do cateter urinário, pois $83,3 \%$ (5/6) dos pacientes que adquiriram infecção urinária polimicrobiana haviam sido cateterizados.

Outros fatores mostraram favorecer o desenvolvimento de ITU complicada; diabetes, neoplasia prostática, hipertensão e longos períodos de permanência em UTI, entre outros, figuraram isolada ou concomitantemente em todos os casos de culturas polimicrobianas. Clarridge et al..$^{(3)}$ compilaram outros dados de fatores de complicação, como sondas de nefrostomia, cálculos urinários e bexiga neurogênica. Fraldas geriátricas podem causar irritação local da pele e infecção fúngica, levando a uma colonização polimicrobiana, e em vários casos ocorre ITU com patógenos não usuais associados a uropatógenos ${ }^{(11)}$.

Neste trabalho optou-se por coletar duas amostras de urina pelas dificuldades operacionais de se obter um 
número maior de amostras. Koneman ${ }^{(12)}$ cita que, no exame bacteriológico quantitativo de urina, uma cultura com desenvolvimento superior a $100.000 \mathrm{UFC} / \mathrm{ml}$ representa $80 \%$ de acerto no diagnóstico de bacteriúria vesical, duas amostras, $91 \%$ e três amostras, $95 \%$. Considerando o efetivo rigor empregado na coleta (supervisionada), o transporte adequado, a conservação em temperaturas de 4 a $8^{\circ} \mathrm{C}$ e a correta semeadura, procurou-se aumentar as chances de acerto utilizando-se apenas duas amostras.

O espectro de uropatógenos encontrados nas ITUs polimicrobianas foi bastante distinto: além de $E$. coli e K. pneumoniae foram isolados Enterobacter spp., S. epidermidis, Candida sp. e estreptococo grupo D não enterococo. Clarridge et al.(3) sugeriram que Escherichia coli, Enterobacter spp., Providencia spp., Serratia spp., Acinetobacter spp. e Pseudomonas spp. são responsáveis pela maioria das ITUs, porém estafilococos coagulase negativos e leveduras podem se comportar como patógenos oportunistas, quando estão diminuídas as defesas do organismo. A ITU polimicrobiana, que em outros contextos é frequentemente considerada sugestão de contaminação de amostra, é comum em ITU complicada ${ }^{(6)}$.

Orrett $^{(7)}$ realizou um estudo em 1998 com 5.089 amostras de urina. Das $1.491(29,3 \%)$ que se apresentaram positivas, $524(35,1 \%)$ eram polimicrobianas: 446 $(85,1 \%)$ continham dois organismos, $69(13,1 \%)$, três e nove $(1,7 \%)$, quatro. Outras amostras de urina foram obtidas de 157 pacientes com urinas polimicrobianas (30\%) e somente 90 (57,3\%) desses indivíduos apresentaram os mesmos organismos nas amostras subsequentes. E. coli foi o isolado mais comum em culturas monobacterianas (42,1\%) e achava-se associado em 16,8\% das culturas polimicrobianas. As bactérias mais encontradas em culturas mistas foram Enterococcus spp. (11,5\%), Klebsiella spp. (21,4\%), Enterobacter spp. $(10,7 \%)$ e
Pseudomonas aeruginosa $(7,6 \%)$, sendo que Staphylococcus saprophyticus ocorreu apenas em culturas monobacterianas.

Neste estudo obteve-se 5,2\% (6/117) de amostras que originaram culturas polimicrobianas. Com base no resultado, é possível afirmar que a adoção de rígidos protocolos de coleta e processamento aliados ao não descarte de amostras polimicrobianas oriundas do ambiente hospitalar, sem antes analisar todos os dados disponíveis, pode propiciar segurança para que o microbiologista libere resultados de uroculturas polimicrobianas.

\section{Conclusão}

Com base no que foi exposto, é possível inferir que uma cultura de urina polimicrobiana, principalmente em ambiente hospitalar, não pode ser automaticamente descartada. Dados clínicos, especialmente a presença de cateter ou suspeita de sepse, bem como doenças associadas (diabetes, prostatite, pielonefrite, entre outras), devem ser relatados ao laboratório, que deverá proceder e interpretar a amostra de maneira adequada.

A confirmação do diagnóstico deve ser realizada com amostras seriadas de urina, observando-se a presença dos mesmos patógenos nas diversas amostras, embora tal procedimento sofra limitações quando a terapia antimicrobiana já foi iniciada. O laboratório necessita observar as indicações clínicas existentes na solicitação do exame, e quando não existentes deve solicitá-las para realizar, de maneira adequada, os procedimentos para diagnóstico das ITUs polimicrobianas. Convém ressaltar a necessidade de estabelecer protocolos rígidos de coleta, transporte e semeadura imediatamente após a coleta do material, possibilitando, assim, a valorização dos uropatógenos presentes sem a interferência de contaminantes.

\section{Referências}

1. ALBINI, C. Cultura de urina: análise das metodologias, interferências sobre os resultados e proposta para padronização. Monografia apresentada ao curso de Especialização em Bacteriologia. Universidade Federal do Paraná, 1994

2. ALBINI, C. A.; SOUZA, H. A. P. H. M.; STINGHEN, A. E. M. Coloração de Gram: como fazer, interpretar e padronizar. 2. ed. Curitiba, PR: Microscience, 2003.

3. CLARRIDGE, J. E.; JOHNSON, J. R.; PEZZLO, M. T. Cumitech $2 B$ : laboratory diagnosis in urinary tract infections. American Society for Microbiology, Washington, D.C., 1998.
4. GOLDMAN, L.; AUSIELLO, D. Cecil textbook of medicine. 23. ed. Phyladelphia: W. B. Saunders Company, 2009.

5. HENRY, J. B. Diagnósticos clínicos \& tratamento por métodos laboratoriais. 20. ed. São Paulo: Manole, 2008.

6. MCCARTER, Y. S.; BURD, E. M.; HALL, G. S. et al. Cumitech 2C: laboratory diagnosis of urinary tract infections. American Society for Microbiology, Washington, D.C., 2009.

7. ORRET, F. A. Significance of polymicrobial bacteriuria in a teaching hospital in Trinidad. Central African Journal of Medicine, v. 44, n. 11, p. 283-6, 1998. 
8. PILONETTO, M; PILONETTO, D. V. Manual de procedimentos básicos em microbiologia clínica. Curitiba: Microscience, 1998.

9. SIEGMAN-IGRA, Y. et al. Polymicrobial and monomicrobial bacteraemic urinary tract infection. Journal of Hospital Infection, v. 28, p. 49-56, 1994.

10. SIEGMAN-IGRA, Y. et al. The significance of polymicrobial growth in urine: contamination or true infection. Scandinavian Journal of Infectious Diseases, v. 25, p. 85-91, 1993.
11. VANCE, D. B. Do you know if incontinent, bedridden nursing home do better overall with a catheter or with disposable underwear? What if they have sacral pressure sores? Annals of Long-Term Care, v. 10, n. 10, p. 50-3, 2002.

12. WINN, W. J.; ALLEN, S.; JANDA, W. et al. Koneman's color atlas and textbook of diagnostic microbiology. Philadelphia: Lippincott Williams \& Wilkins, 2006. 